
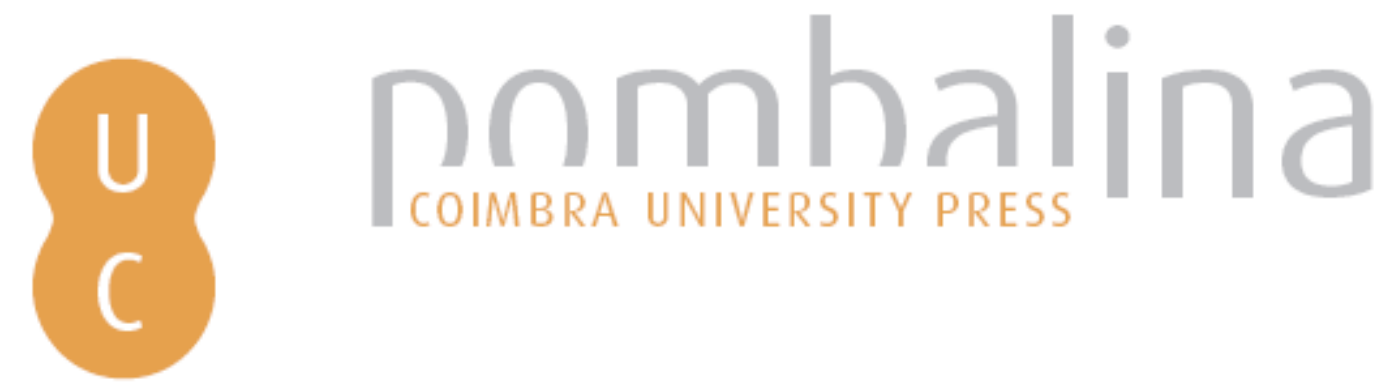

\title{
Gaining benefits from adversity: the need for systems and frameworks to maximise the data obtained from wildfires
}

\author{
Autor(es): $\quad$ Chong, Derek M.; Cirulis, Brett A.; Duff, Thomas J.; Walsh, Sean F.; \\ Penmanb, Trent D.; Tolhust, Kevin G.
}

Publicado por: Imprensa da Universidade de Coimbra

URL persistente:

URI:http://hdl.handle.net/10316.2/34461

DOI:

DOI:http://dx.doi.org/10.14195/978-989-26-0884-6_85

Accessed : $\quad$ 26-Apr-2023 16:30:38

A navegação consulta e descarregamento dos títulos inseridos nas Bibliotecas Digitais UC Digitalis, UC Pombalina e UC Impactum, pressupõem a aceitação plena e sem reservas dos Termos e Condições de Uso destas Bibliotecas Digitais, disponíveis em https://digitalis.uc.pt/pt-pt/termos.

Conforme exposto nos referidos Termos e Condições de Uso, o descarregamento de títulos de acesso restrito requer uma licença válida de autorização devendo o utilizador aceder ao(s) documento(s) a partir de um endereço de IP da instituição detentora da supramencionada licença.

Ao utilizador é apenas permitido o descarregamento para uso pessoal, pelo que o emprego do(s) título(s) descarregado(s) para outro fim, designadamente comercial, carece de autorização do respetivo autor ou editor da obra.

Na medida em que todas as obras da UC Digitalis se encontram protegidas pelo Código do Direito de Autor e Direitos Conexos e demais legislação aplicável, toda a cópia, parcial ou total, deste documento, nos casos em que é legalmente admitida, deverá conter ou fazer-se acompanhar por este aviso.

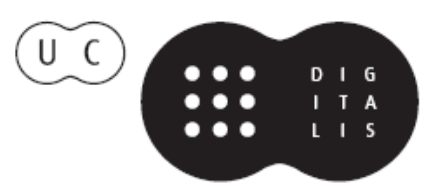




\section{ADVANCES IN}

Forest Fire

\section{RESEARCH}

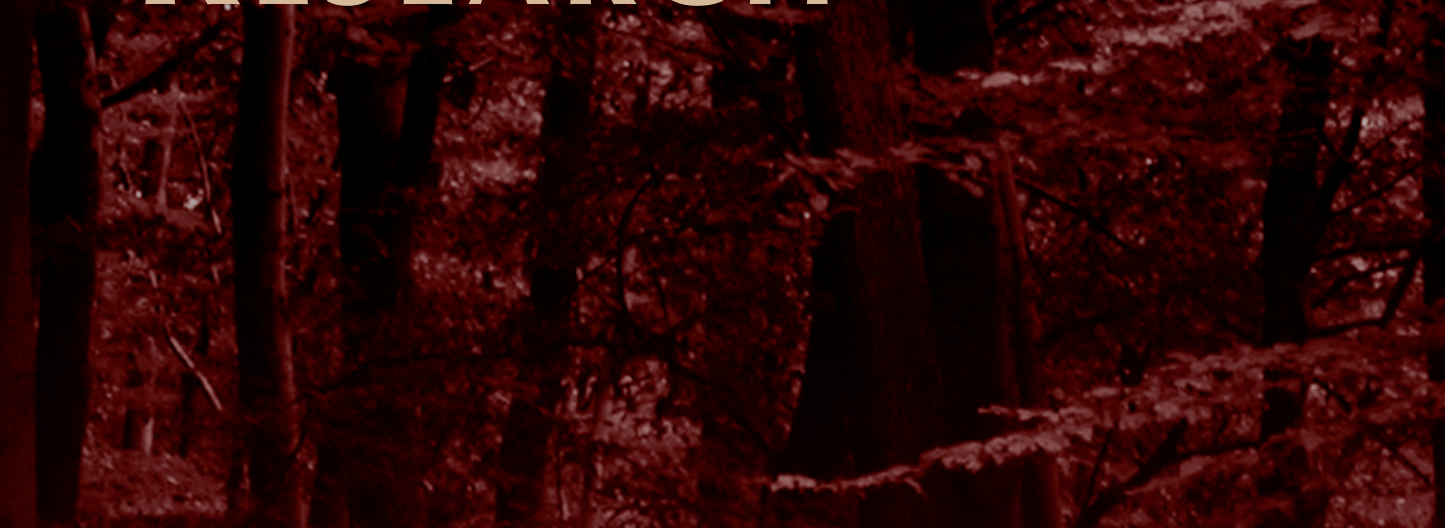

\section{DOMINGOS XAVIER VIEGAS}

\section{EDITOR}




\title{
Gaining benefits from adversity: the need for systems and frameworks to maximise the data obtained from wildfires
}

\author{
Thomas J. Duff ${ }^{a}$, Derek M. Chong ${ }^{\mathrm{a}}$, Brett A. Cirulis ${ }^{\mathrm{a}}$, Sean F. Walsh ${ }^{\mathrm{a}}$, Trent D. Penman ${ }^{\mathrm{b}}$, Kevin G. \\ Tolhust $^{\mathrm{b}}$ \\ ${ }^{a}$ University of Melbourne, Burnley,Victoria Australia 3121, tjduff@ unimelb.edu.au, \\ derekmoc@unimelb.edu.au, sean.walsh@unimelb.edu.au \\ ${ }^{b}$ University of Melbourne, Creswick, Victoria Australia 3363, trent.penman@unimelb.edu.au, \\ kgt@unimelb.edu.au
}

\begin{abstract}
The organisations that manage wildfires are expected to deliver scientifically defensible decisions. However, the limited availability of high quality data restricts the rate at which research can advance. The nature of wildfires contributes to this; they are infrequent, complex events and occur rapidly. While some information about wildfires is usually collected, it is often not of an appropriate standard for research. Valuable information may be discarded or not collected as it is not seen as operationally useful. The harmonisation of fire data management worldwide could increase the availability and quality of information for research. We propose a three tiered approach where agreements are created to standardise data quality, define the scope of information to be collected and establish access protocols for sharing. Standardisation of data collection would facilitate the aggregation of data throughout the world, providing leverage on data collected and reduce unnecessary duplication. If the scope of collection can be expanded, there are a wide range of research fields that stand to benefit. Appropriate data sharing between agencies would increase the value of the data and enable robust conclusions to be reached. It is imperative that the losses caused by severe fires are not in vain; losses should be offset by efforts to maximise the information obtained, helping to prevent a repeat of such events in the future.
\end{abstract}

Keywords: bushfire, data, enquiry, experimental design, framework, investigation, observations

\section{Introduction}

In the last decade there has been a high number of catastrophic wildfires throughout the world. In Australia alone, fires burning under extreme weather conditions have resulted in mass house loss in the state Victoria in 2009 (Cruz et al. 2012), Western Australia in 2011 and New South Wales and Tasmania in 2013 (Kepert et al. 2013). These fires have resulted in substantial social, economic and environmental impacts and recovery activities may take many years. In response to the increasing threat of fire, land managers in vulnerable jurisdictions have made substantial investments in mitigation, preparedness, response and recovery capabilities (McLoughlin 1985; Gebert and Black 2012). Due to the complexity of managing fires, it is not always clear how best to make investments to reduce fire impacts. As a consequence, there has recently been a rapid development of tools to aid decision support for landscape managers in fire prone environments. These include the development of systems that can evaluate complex information to optimise investment levels (Prestemon et al. 2008), resource placement (Chow and Regan 2011) or provide information on fire behaviour to aid suppression planning (Sullivan 2009). The development of systems that can support decisions for complex landscape scale events requires research that can differentiate the contributions of numerous interacting factors to an outcome. The analysis of such 'noisy' events requires large amounts of data in order for models to have adequate predictive power. However, the nature of wildfires means that obtaining such data is challenging. 
Wildfires typically occur with limited notice, burning in heterogeneous natural landscapes driven by complex weather patterns (Cary et al. 2009). The behaviour of fires and their subsequent impacts are consequently the product of multiple interacting parameters and as a result, it can be difficult to quantify relationships and predict outcomes. While some research into wildfires has attempted to address this problem through the use of controlled experiments (Cheney et al. 2012), the need to safely manage trials has meant that it is prohibitive to use such experiments to evaluate emergent fire behaviour under extreme conditions. However these events are where losses are typically highest and are consequently of greatest interest to managers (Strauss et al. 1989). In addition, many elements of fire management need to be in a realistic landscape context to be relevant; activities such as evacuation or fire suppression are difficult to emulate experimentally.

As research into fields relating to extreme fire behaviour cannot be done experimentally, alternative sources of information are required to allow systematic management planning. The sole remaining way to source observations of fire dynamics is to collect information from fires as they occur. While up to date information is recognised as a critical need for managing 'going' fires, to date there has been a limited focus on collecting information during fires for post-fire analysis. Typically, post-fire investigations are driven by coronial or governmental requirements; it is rare for there to be a systematic process for collecting information during and after severe fires specifically for research purposes. Without such information, fire research and the development of subsequent decision support systems will stall. Case-study fires are commonly used in research; however there is currently no formal process for ensuring the data collected during and post-fire is appropriate for meeting research requirements.

While up to date information is recognised as a critical need for managing 'going' fires, to date there has been a limited focus on collecting information during fires for post-fire analysis. We contend that the collaborative development of a fire data management framework across multiple jurisdictions will have broad benefits for all involved. It has the potential to enhance cross border collaboration, increase the power of datasets and make research findings more internationally relevant.

\subsection{The current state of data management}

In jurisdictions where fires occur, it is typical that some information about wildfires is collected. This may be details of ignitions (Penman et al. 2013), severity (Harris et al. 2012) or economic impact (Donovan and Noordijk 2005). However there is currently no unified set of standards or methodologies that define a) what information needs to be collected and b) when collected, what data standards are appropriate. Furthermore there is no standardised system for sharing information that has been collected. As a result, the information that is generated during a fire may not be of an appropriate standard for research, it may be discarded if it is not seen as operationally useful or it may not be seen as important and it may not be collected at all (Figure 1). 


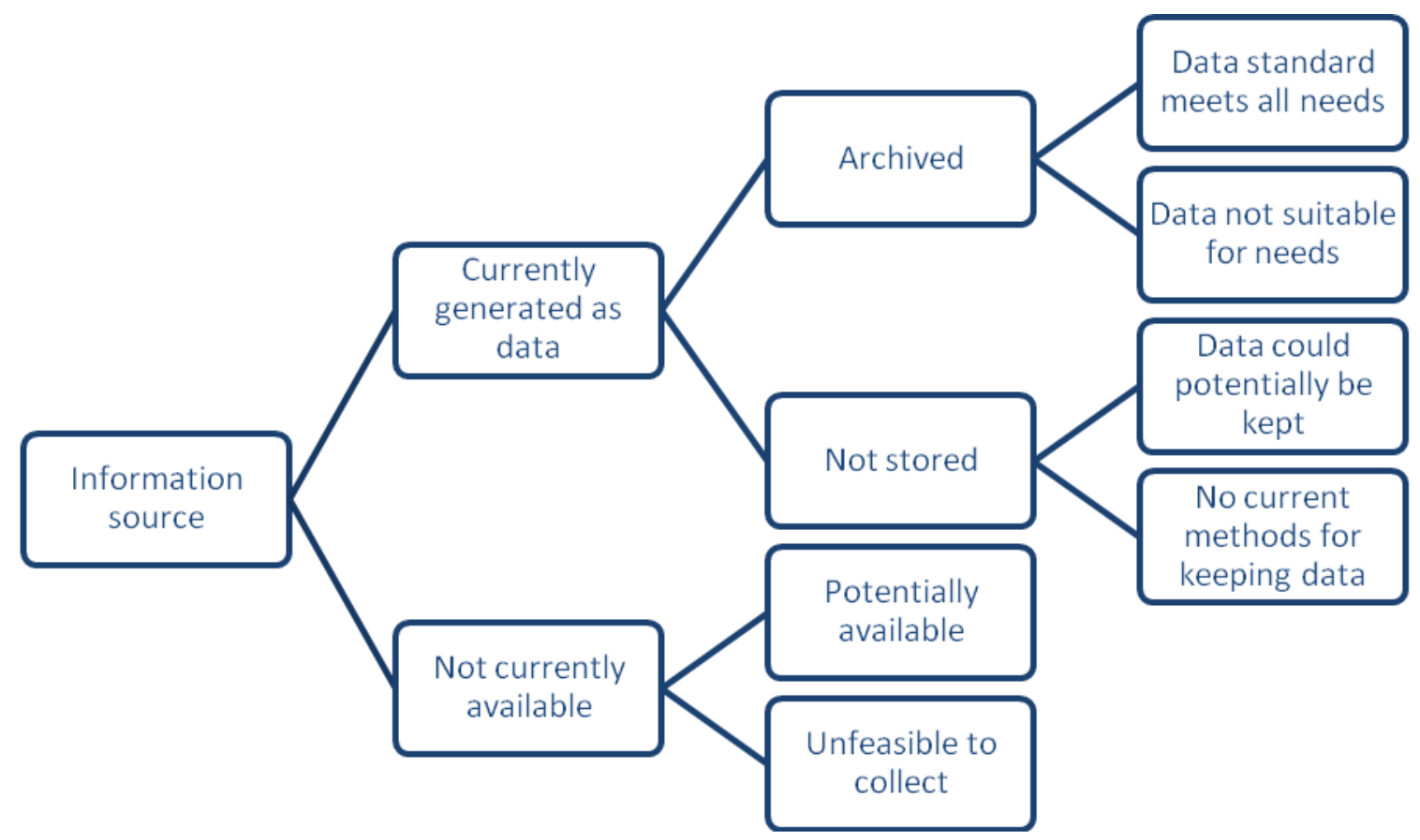

Figure 1. Data hierarchy for information generated at a fire incident

\section{Proposed methods}

\subsection{Determining the breadth of information requirements}

Experimental emulation of the most extreme fire conditions is not possible, particularly as many elements of fire management need to be in a real landscape context to be relevant; activities such as evacuation or fire suppression are difficult to emulate experimentally. At the moment, any agency managing a fire incident has specific information requirements to meet its daily operational and planning needs. While meeting these needs has been the priority for managers, there are potentially other needs that are not being met. These may be the needs of external groups (such as university researchers), other intra-governmental agencies (such as the police), inter-governmental agencies (such as the fire management agencies of other jurisdictions or states) or future needs within departments. In addition, at small scales (such as in relation to a single fire) some forms of information may not seem informative. However, when pooled, sample size and consequent model power is increased and the information may then be much more valuable. Without consistent data collection and management protocols, fire information may be useful only within the jurisdiction in which it is collected. Consequently to get the maximum value from information, discussions should be held at the highest level possible - the ultimate benefit would result if data could be effectively pooled across international borders, regions and continents. To do this agreement must be reached on three broad areas; scope - what to collect, standards - how to collect, and access - how to share.

Scope: It would be necessary to obtain agreement on the scope of data to be collected. While there is typically a focus on fire behaviour and fuel, information regarding suppression strategies, logistics and command structures are often overlooked. Such information is invaluable for operational research. To optimise the scope of data collected, fire management agencies would need to look more broadly than within their organisations. Other interested parties include other emergency services, utilities, administration bodies and universities. 
Standards: Data will need to be standardised, with quality controls on types, units, resolutions, formats and metadata. Standardised methodologies would greatly enhance cross jurisdiction collaboration and allow for broader, more widely applicable studies.

Access: In addition to data collection protocols, for value to be extracted it is important to ensure that contributing agencies are able to access the information provided by others. This is likely to require licensing agreements and the establishment of repositories. There is the potential for privacy issues to manifest, so limitation of access for some datasets may be a consideration.

The degree of difference in fire data collection protocols within a single country can be demonstrated with a search of the Australian public geospatial data directories using the term 'fire'. Table 1 indicates that there are orders of magnitude in difference between the numbers of records available for each state. Wildfires occur within all states of Australia.

Table 1. Number of spatial records discoverable using the term 'fire' on the 5/2/2014 in Australian state based spatial data directories

\begin{tabular}{lr}
\hline State & Records available \\
\hline Australian Capital Territory & 48 \\
New South Wales & 42 \\
Northern Territory & 2 \\
Queensland & 65 \\
South Australia & 4 \\
Tasmania & 11 \\
Victoria & 169 \\
Western Australia & 149 \\
\hline
\end{tabular}

The three areas of fire information that need to be unified are described briefly below.

\subsection{Data standards}

Of the information typically stored by land managers in relation to fire, a large proportion of the data relates to infrastructure and other relatively invariant landscape attributes. There are a number of datasets that are in common between various states (for example fire history and ignition location), however metadata indicates that there is potentially substantial variation in the collection standards both within and between agencies (Walsh et al. 2007). While there are some barriers to the complete standardisation of data collection due to scale, access and technological issues, the degree of difference between the state data collection methodologies means there are likely to be interpretation issues when attempting inter-state investigations. In addition, while many agencies collect information on fire perimeters, for it to be of practical use to science, accessory data such as fuel details, topography, local weather observations, assets at risk and infrastructure must also be made available. Inconsistencies between jurisdictions in accessory data can further compound errors due to inconsistent fire data. For example, while approaches to evaluating fuel have been converging, there is still no system that is consistently applied or is suitable for all jurisdictions and vegetation types in Australia (Gould and Cruz 2012).

Inconsistencies in data can result in severe issues with regards to its access. Differing scales, units and margins of error can make it difficult to determine equivalence between datasets and can confound analysis. As there is much in common in the vegetation, weather and fire behaviour between states in Australia, it would be expected that many of the findings in one jurisdiction would also be appropriate in another. However with differing information, cross-border collaboration and model application is constrained. A common issue with fire science is that due to the complexity, rapidity and infrequent 
nature of wildfire incidents it is difficult to collect enough observational data to provide suitable replication for statistical analysis. Standardisation of data collection will facilitate the aggregation of data throughout not only Australia, but the world, providing leverage on data collected, reduce unnecessary duplication and allow robust conclusions to be reached sooner and with less expense.

\subsection{Scope of data}

Considering Australia as a case study, there are a small number of data sets that are consistently collected by the majority of states despite the fact that wildfires are an issue to varying degrees in them all (Walsh et al. 2007). We believe that of the data available, only a small portion of data relevant to fire research is currently being archived as 'fire data' and made available for future needs. While it is common to collect information on impacts such as final perimeters and the locations of house losses, other information pertaining to fire spread predictions, firefighter accomodation and suppression deployments is not available. Table 2 provides an indication of potential information that may be generated; however this list is not exhaustive. Very few of the information sources listed are routinely collected.

Table 2. Information sources potentially available for typical fire incidents. Information is grouped by research group and incident management system category (AIIMS ICS 2013)

\begin{tabular}{|c|c|c|c|}
\hline Research Potential & Information source & AIIMS ICS category & Routinely available? \\
\hline \multirow{10}{*}{$\begin{array}{l}\text { Management / Social } \\
\text { Science }\end{array}$} & Incident type & Incident Control & \\
\hline & Escalation / de-escalation & Incident Control & \\
\hline & Emergency declarations & Incident Control & \\
\hline & Control structures & Incident Control & \\
\hline & Ignition point / points & Investigation & Y \\
\hline & Ambulance callouts & Investigation & \\
\hline & Hospitalisation by cause & Investigation & \\
\hline & Insurance claims & Investigation & \\
\hline & Fencing / stock losses & Investigation & \\
\hline & Urban infrastructure & Investigation & \\
\hline \multirow{10}{*}{ Management Science } & Vehicle types & Logistics & \\
\hline & Supplies & Logistics & \\
\hline & Catering & Logistics & \\
\hline & Accommodation & Logistics & \\
\hline & Medical & Logistics & \\
\hline & Communications & Logistics & \\
\hline & Facilities & Logistics & \\
\hline & Finances & Logistics & \\
\hline & Resourcing & Logistics/Planning & \\
\hline & Emergency calls & Investigation & \\
\hline \multirow[t]{8}{*}{ Operational Research } & Weather radar & Intelligence & \\
\hline & Satellite images & Intelligence & \\
\hline & Weather Forecasts & Intelligence & \\
\hline & Aircraft GPS tracks & Operations & \\
\hline & Vehicle GPS tracks & Operations & \\
\hline & Response structures & Operations & \\
\hline & Deployments & Planning & \\
\hline & Situation reports & Operations/IC control & \\
\hline \multirow[t]{6}{*}{ Fire Behaviour } & Progression isochrones & Intelligence & \\
\hline & Ground/air observations & Intelligence & \\
\hline & Line scans & Intelligence & \\
\hline & Suppression strategies & Operations/Planning & \\
\hline & Final perimeters & Planning & Y \\
\hline & Fire behaviour predictions & Intelligence & \\
\hline
\end{tabular}


Weather observations

Fuel /fire history

Objectives

Media strategy

All

Recovery

Post fire impacts
Intelligence

Planning

Planning

Public information

All

All

A secondary issue relating to data scope relates to the type of fires that are evaluated in detail. Due to the coronial and reactive nature of large fire investigations, there is a greater likelihood of data being available for extreme events. Data that is consistently collected at these fires includes maps of the final fire perimeter, headfire rates of spread, post-fire aerial imagery, weather conditions, fuel properties and the locations of house losses and deaths. However for more minor fires, the quality of information is generally much poorer. While it may be argued that larger fires are more important to study due their disproportionate impact, a strong counter argument is that some of the smaller fires may have had the potential to be catastrophic but effective preparedness or response measures prevented that from eventuating. Correspondingly it could be argued that smaller fires that occur under severe weather conditions deserve greater attention rather than less.

As it stands currently, a bias of data collection towards particular fire types has the potential to confound research and lead to incorrect conclusions. For example, evidence suggests that the predominant mechanism of house loss under the most extreme fire conditions differs to that under less severe but more common conditions. In addition, fire suppression and fuel reduction are less likely to be seen to be effective under extreme conditions; however they have clear value in preventing incidents from escalating under less severe conditions.

An additional issue is information decay. While information from some sources is robust, providing for simple post-fire collation, other forms are more transient. Highly temporally specific data is common in fires -it is important to be able to track and understand fast moving fire fronts. However if detailed information is not recorded at the time of the fire, information is easily lost and there may be limited opportunity to reconstruct occurrences post fire. This means that management agencies need to develop pro-active data policies. There need to be processes in place to actively target and record information while it is available and before its quality decays. While there is likely to be some overhead cost to this information gathering, such data can lead to improved decision support tools which reduce the overall overheads of fire management. Examples of information that can be transient include the location and rate of spread of fire fronts, the location, number and activity of suppression resources, and the behaviour and activity of civilians in the fire zone. After a fire event, there is greater luxury to collect data from some sources at a slower rate, however it remains important to actively target and record information before it is lost.

The scope of information being collected during and after fires is currently very limited. If information collection can be expanded, there are a wide range of research fields that stand to benefit. While the nature of Australian Eucalyptus forests mean that embers can play a disproportionate role in fire spread than in other forest types throughout the world (Cruz et al. 2012), fire remains a physical process. As such, standardisation of the scope and quality of data would be of greater benefit if it could be on an international scale, enabling research projects to be more expansive and enabling conclusions to be more broadly applicable.

\subsection{Availability of data}

Even if data is of high quality and correctly scoped, fire research may still be hindered by lack of access. This results from two primary issues. The first is that can be difficult for anyone (both internal and external to management agencies) to determine what data is being stored and is available. While spatial data directories have made substantial progress towards transparency of fire information in some jurisdictions, not all information that is collected is formally stored in a manner that is discoverable through such systems (e.g. Table 2). Much of the information gathered during a fire by a 
managing agency would be stored in some manner, however only a small proportion is centralised and can be accessed using a query focused on a particular fire. The discovery of such information can require substantial resources; coronial reconstructions of fires take significant time and money to reconstruct particular events, even though much of the necessary information would be generated and available at the time of the event. Currently, the data recorded during fires shows limited consideration to the likely post-fire reconstruction information needs.

A second issue relates to data infrastructure. States, and within states; agencies, currently independently manage their own information. Obtaining data for a large geographic area is likely to mean that access must be negotiated from a number of different bodies. Once data is available, variability in formats and resolutions mean that further processing is typically required to ensure information from various sources is compatible and equivalent. Both obtaining data access and data processing can pose a significant time burden on users. The development of tools to access shared information is a necessary step towards effective cooperation and collaboration on informational needs. One issue that would need to be overcome in relation to information sharing is what limits would need to be applied. Many countries and states now have legislated privacy laws. Some of the information collected during fires may full under the jurisdiction of such laws - undeniably information relating to fatalities and events at particular residences is going to be sensitive and require some limitations on sharing under specific circumstances.

More broadly, the development of systems to recognise, tag, store and share fire related information could greatly reduce data discoverability issues. Furthermore, appropriate data sharing between agencies would create economies of scale, and more comprehensive data would enable more robust conclusions to be reached. If methods, scope and storage of fire data were standardised, substantial benefits may be realised, including greater success in preventing impacts from major fires in the future.

\section{Proposed process}

The development of a fire information system is expected to be a complex process as it would require the commitment and collaboration of a large number of emergency service agencies in disparate jurisdictions. It would be necessary to develop any new framework as a multi-stage project.

- Phase one would be to audit the 'status quo' and determine in detail how information is being managed within agencies.

- Phase two would be to undertake a needs analysis, evaluating informational requirements of both agencies and scientists. This would need to be carefully planned to ensure that findings are broadly applicable and not merely convenient for a single country.

- Phase three would be to analyse information sources and end-user needs to address data 'gaps', making recommendations on data standards, scope and storage mechanisms. This must also include the potential for the recognition of new needs and the inclusion of novel information sources. As technology is continually improving, the future improvement of information collection standards and the inclusion of new sources must remain an option even when a data framework is operating.

- Phase four would focus on the establishing compatible systems between agencies with an overarching aim to develop a centralised system for discovering and accessing data. This would require some reciprocal understanding in relation to data access, licensing, privacy and public availability.

To be effective, this process should be cooperative. While a considered analysis of informational needs will have immediate tangible benefits for a single agency, the greatest benefit overall would be the potential for cross border cooperation and increased research leverage. 
We suggest that initial steps towards establishing an effective fire information system should be:

- The allocation of a unique code to each reported fire ignition. Any information pertaining to a particular ignition should be associated with this code. To avoid the risk of duplicates, a composite code could be used such as country/state/year/fire_number. Such a code would assist in the development of databases for the archiving of data.

- The existing fire command and control system should be used as a template for structuring and storing fire information. This will ensure that all relevant aspects of a fire are considered. Each function group (i.e Planning, Intelligence etc.) should be responsible for ensuring that information is collected at a suitable standard (Australasian Fire and Emergency Service Authorities Council 2013).

Following this it will be necessary for substantial communication between agencies. This would need to be a forum style process, where views and perspectives can be shared to ensure the proposed procedures and policies best meet the needs of all involved.

The development of any new standards and processes requires careful consideration. Poorly designed standards can 'lock in' unsatisfactory methods or result in competing standards where the interested parties have not come to full agreement (Monroe 2011).

\section{Summary}

A common issue with fire science is that due to the complexity, rapidity and rarity of fire incidents it is difficult to collect enough observational data to provide suitable replication for statistical analysis. Standardisation of data collection will facilitate the aggregation of data throughout the world, providing leverage on data collected, reduce unnecessary duplication and allow robust conclusions to be reached sooner and with less expense.

Land and emergency response organisations are increasingly being expected to deliver scientifically defendable decisions and to demonstrate continuous improvement in management and resource use. The limited availability of high quality data restricts the rate at which research can advance and predictive capacity can improve. It is imperative that the losses caused by severe fires are not in vain; losses should be offset by efforts to maximise the information obtained, helping to prevent a repeat of such events in the future.

\section{References}

Australasian Fire and Emergency Service Authorities Council (2013) 'Australasian Inter-service Incident Management System (AIIMS) 4th Edition.' (Australasian Fire and Emergency Service Authorities Council: Melbourne, Australia)

Cary, GJ, Flannigan, MD, Keane, RE, Bradstock, RA, Davies, ID, Lenihan, JM, Li, C, Logan, KA, Parsons, RA (2009) Relative importance of fuel management, ignition management and weather for area burned: evidence from five landscape fire succession models. International Journal of Wildland Fire 18, 147-156.

Cheney, NP, Gould, JS, McCaw, WL, Anderson, WR (2012) Predicting fire behaviour in dry eucalypt forest in southern Australia. Forest Ecology and Management 280, 120-131.

Chow, JYJ, Regan, AC (2011) Resource location and relocation models with rolling horizon forecasting for wildland fire planning. INFOR 49, 31-43. 
Cruz, MG, Sullivan, AL, Gould, JS, Sims, NC, Bannister, AJ, Hollis, JJ, Hurley, RJ (2012) Anatomy of a catastrophic wildfire: The Black Saturday Kilmore East fire in Victoria, Australia. Forest Ecology and Management

Donovan, GH, Noordijk, P (2005) Assessing the accuracy of wildland fire situation analysis (WFSA) fire size and suppression cost estimates. Journal of Forestry 103, 10-13.

Gebert, KM, Black, AE (2012) Effect of suppression strategies on federal wildland fire expenditures. Journal of Forestry 110, 65-9.

Gould, J, Cruz, MG (2012) Australian Fuel Classification: Stage II.(Ed. G Featherstone.) (Australasian Fire and Emergency Services Council (AFAC) and the Commowealth Science and Industrial Research Organisation (CSIRO): East Melbourne, Australia). [Accessed

Harris, S, Anderson, W, Kilinc, M, Fogarty, L (2012) The relationship between fire behaviour measures and community loss: an exploratory analysis for developing a bushfire severity scale. Natural Hazards 63, 391-415.

Kepert, JD, Fawcett, RJB, Tory, KJT, W. (2013) Applications of very high resolution atmospheric modelling for Bushfires. In 'AFAC13 Shaping Tomorrow Together. Melbourne, Australia'. (Ed. RP Thornton) (Bushfire Cooperative Research Centre)

McLoughlin, D (1985) A framework for intergrated emergency management. Public Administration Review 45, 165-172.

Monroe, RP, 2011. Standards. XKCD. http://xkcd.com/927/,

Penman, TD, Bradstock, RA, Price, O (2013) Modelling the determinants of ignition in the Sydney Basin, Australia: implications for future management. International Journal of Wildland Fire 22, 469-478.

Prestemon, JP, Abt, K, Gebert, K (2008) Suppression cost forecasts in advance of wildfire seasons. Forest Science 54, 381-396.

Strauss, D, Bednar, L, Mees, R (1989) Do one percent of forest fires cause ninety-nine percent of the damage? Forest Science 35, 319-328.

Sullivan, AL (2009) Wildland surface fire spread modelling, 1990-2007. 1: Physical and quasiphysical models. International Journal of Wildland Fire 18, 349-368.

Walsh, DJ, Rumba, KE, Hoare, J, Parsons, M, Thackway, R (2007) Reporting fire in Australia's forests and vegetation. Bureau of Rural Sciences, Canberra, Australia. 